\title{
Almond milk fermented with different potentially probiotic bacteria improves iron uptake by intestinal epithelial (Caco-2) cells
}

\author{
Neus Bernata* $^{\text {a }}$, Maite Cháfer ${ }^{\mathrm{a}}$, Amparo Chiralta ${ }^{\mathrm{a}}$, José Moisés Laparra ${ }^{\mathrm{b}}$, And \\ Chelo GonzÁlez-Martínez \\ ${ }^{a}$ Instituto de Ingeniería de Alimentos para el Desarrollo. Universitat Politècnica de València, Camino de Vera \\ s/n, 46022 Valencia, Spain \\ b Microbial Ecophysiology and Nutrition Laboratory. Instituto de Agroquímica y Tecnología de Alimentos \\ (CSIC). Av. Agustín Escardino, 7. 46980 Paterna, Valencia, Spain \\ ${ }^{*}$ Corresponding author \\ neuberpe@upvnet.upv.es \\ TEL: +34963877056 \\ FAX: +34963877956
}

Received: 6 Mars 2014; Published online: 18 April 2015

\begin{abstract}
New fermented almond milks were developed, using different potentially probiotic bacteria, in order to meet the current demand for healthy, versatile non-dairy products. An in vitro digestion/Caco2 cell model was used to evaluate the effect of both non-fermented and fermented almond milks on the mitochondrial enzymatic activities of enterocytes. Moreover, macrophages were challenged with the in-vitro digested samples and the production of pro-inflammatory biomarkers TNF- $\alpha$ and IL-6 was quantified. Enzymatic activities of cell cultures seemed to be stimulated by the exposure to both fermented and non-fermented almond milks. Both biomarkers decreased $(\mathrm{p}<0.05)$ in fermented almond milks with either B. bifidum or B. longum. Results showed that fermented almond products favored the energetic metabolism of enterocytes and had a lower inflammatory response than non-fermented almond milk, suggesting its benefits for the management of allergies/intolerances. Moreover, the fermentation process enhanced the uptake of iron by Caco-2 cells, especially when using L. rhamnosus and either $B$. bifidum or $B$. longum as starters, thus improving the product bioactivity. Therefore, new nondairy fermented products with functional properties were developed, which might be positioned as alternatives to cow-milk products for sensitized groups of population (allergic and/or intolerant to cow milk or anemic population, among others).
\end{abstract}

Keywords: Almond milk; Fermentation; Probiotics; Iron availability; Inflammation

\section{Introduction}

The current alarming increase in the incidence of allergic diseases in both children and adults in developed countries has been attributed to the so-called "hygiene hypothesis"; this theory suggests that the increased level of hygiene in both the environment and the food supply leads to a reduced exposure to a variety of microbes, which, early in life, is a crucial factor in the development of allergies (Björkstén, 2009). Indeed, several prospective follow-up studies have found that alterations in gut microbiota precede allergy development (Kalliomäki, 2010). Hence, recent clinical allergy researches have principally focused their attention on the manipulation of 
gut microbiota composition (Kalliomäki et al., 2010). Nowadays, probiotics, prebiotics and synbiotics (combination of pre- and probiotics) are considered as good tools with which to elicit changes in the gut biomass composition, since they can improve and stimulate beneficial gut microflora, among other effects that are beneficial for the health. Since the late 1990s, over 30 randomized clinical trials have been published, in which probiotics have been used either in the treatment or prevention of allergies (mainly atopic diseases) (Kalliomäki et al., 2010). Hence, considering the high prevalence of atopic disease in childhood in the industrialized countries (Anandan, Nurmatov, van Schayck, \& Sheikh, 2010), the use of yoghurt-type foods as carriers of probiotics and/or synbiotics would be helpful as a means of attaining the either preventive or prophylactic treatment in this targeted population. Moreover, despite the little known and untrustworthy concept of functional food, consumers are familiar with yoghurt-type products and consider them as healthy (Annunziata \& Vecchio, 2011), which would facilitate the inclusion of such functional fermented products in their diets.

The immunomodulatory effects of fermented dairy-milks, casein hydrolysates and soybeverage caused by lactic acid bacteria have been widely reported (Baroja, Kirjavainen, Hekmat, \& Reid, 2007; Sutas et al., 1996; Wagar, Champagne, Buckley, Raymond, \& Green-Johnson, 2009). However, in addition to the allergenic proteins, both matrices might provoke iron deficiencies in infants and toddlers. On the one hand, the calcium together with the casein provided by cow-milk are seen to inhibit the absorption of dietary non-heme iron, in addition to the intestinal blood loss observed in approximately $40 \%$ of infants during feeding with cow-milk and/or its derivatives (Agostoni \& Turck, 2011). On the other hand, soya-based products contain phytates, which negatively interfere in the absorption of iron, among other minerals (Artazcoz, 2007).

By contrast, almond milk has not been reported to interfere negatively in iron absorption. Indeed, almonds have high anti-oxidant activity owing to the $\alpha$-tocopherol and polyphenolic constituents (Chen, Lapsley, \& Blumberg,
2006), which might improve the bioavailability of dietary iron. As it has been reviewed, although non-heme iron is easily oxidized (not bioavailable) due to the rise of $\mathrm{pH}$ in the lumen, the presence of reductants from food can maintain this micronutrient in its reduced form and, therefore, positively improve its absorption (Miret, Simpson, \& McKie, 2003). Moreover, almond milk is considered an appropriate alternative to cow-milk, since, besides the healthy lipid profile, it has a low ratio of $\mathrm{Na} / \mathrm{K}$ and a balanced ratio of $\mathrm{Ca} / \mathrm{P}$ (Luengo, 2009).

Nevertheless, with regards to the inflammatory response, there is lack of data concerning nut beverages, and least when it comes to derivative fermented products. Only recently has data appeared on almonds (Rajaram, Connell, \& Sabate, 2010), in which the authors studied whether, in addition to the lowering of blood lipids, monounsaturated fat-rich almonds influenced other coronary heart disease risk factors, such as inflammation. The study concluded that incorporating about $68 \mathrm{~g}$ almonds in a 2000 kcal cholesterol-lowering diet decreased serum E-selectin (molecules which are indicative of endothelial dysfunction) and C-reactive protein (sensitive marker of inflammation that, in high concentrations, is strongly linked with coronary events, stroke and peripheral vascular disease) in healthy men and women.

Although around $50 \%$ of almond composition is fat, intakes of $7 \mathrm{~g}$ per day of this nut have been shown to reduce low-density lipoprotein cholesterol concentration by $1 \%$ (Sabaté, Haddad, Tanzman, Jambazian, \& Rajaram, 2003) and up to $84 \mathrm{~g}$ per day can be consumed without weight gain (Chen et al., 2006). In addition, these nuts have a low glycemic index (they do not adversely impact insulin sensitivity) (Chen et al., 2006) and have been found to possess prebiotic effects, since they stimulated the growth of gut bifidobacteria and Eubacterium rectale (Mandalari, Nueno-Palop, Bisignano, Wickham, \& Narbad, 2008). Hence, taking into account the health benefits of almond intake, almond milk might be considered as a good food matrix with which to obtain healthy fermented products. Moreover, if the fermentation process is carried out by potentially probiotic bacteria, the developed fermented product could be useful as a means 
Fermented almond milks improve bioavailability of iron $\mid 51$

of preventing some immunomodulatory diseases, such as allergies.

The Caco-2 cell line, commonly used in conjunction with in vitro digestion techniques, is a useful model for studying intestinal human iron uptake, which it allows to occur simultaneously with food digestion, and is generally regarded as the best available intestinal cell model for studying the mechanisms associated with vectorial iron transport (Glahn, Lee, Yeung, Goldman, \& Miller, 1998). In addition, the macrophage-derived RAW 264.7 cell line expresses key genes and proteins of principal pathways for the production of regulatory cytokines (Novak, Babcock, Jho, Helton, \& Espat, 2003) and constitutes a cell model used worldwide and a useful tool with which to study the inflammatory response(s) and metabolic activity promoted by food-derived components while still maintaining a rapid and inexpensive system (Deepika, Rastall, \& Charalampopoulos, 2011; Kabeerdoss et al., 2011).

The aim of this study, therefore, was to evaluate whether almond milk, fermented with different potential probiotic bacteria, affects both the energetic metabolism in intestinal cells and the production of pro-inflammatory biomarkers in order to gain insights into the potential benefits of the designed products for the consumer's gut health.

\section{Materials and Methods}

\subsection{Preparation and fermentation of almond milk}

Almond milk was produced by soaking and grinding almonds (Prunus amygdalus L. cv. dulcis) supplied by Frutos Secos 3G S.L. (Valencia, Spain). The extraction was carried out in the Sojamatic ${ }^{\circledR} 1.5$ (Barcelona, Spain), equipment specifically designed for the production of vegetable milks, using a nut:water ratio of $8: 100$. The milky liquid obtained was then microfluidized in a high pressure homogenizer (M110P model; Microfluidics International Corporation, Westwood, MA, USA) by applying 172 $\mathrm{MPa}$, sterilized $\left(121{ }^{\circ} \mathrm{C} / 15 \mathrm{~min}\right)$ and subsequently cooled down to $37^{\circ} \mathrm{C}$ (fermentation tem- perature).

Lactobacillus rhamnosus CECT 278, Lactobacillus plantarum 3O9, Bifidobacterium bifidum CECT 870, Bifidobacterium longum CECT 4551, Streptococcus thermophilus CECT 986, Lactobacillus delbrueckii subs. Bulgaricus CECT 4005 were used as starters, pure or mixed, as shown in Table 2. All the bacteria were purchased from CECT (Paterna, Spain), with the exception of the L. plantarum $3 \mathrm{O} 9$ strain, which was isolated from Guirra sheep milk and selected as a probiotic in previous studies (Amorocho Cruz, 2011). For the preparation of starters inoculum, the strains were independently incubated for $24 \mathrm{~h}$ in their selective broths and then centrifuged at 100 g (Medigriger-BL-S, JP-Selecta; Barcelona, Spain) for $10 \mathrm{~min}$ at $4{ }^{\circ} \mathrm{C}$ to re-suspend the pellet in PBS-1x buffer $(10 \mathrm{mmol} / \mathrm{L}$ phosphate, 137 $\mathrm{mmol} / \mathrm{L} \mathrm{NaCl}, 2.7 \mathrm{mmol} / \mathrm{L} \mathrm{KCl}, \mathrm{pH}$ 7.4) until reaching strain concentrations of $10^{8} \mathrm{cfu} / \mathrm{mL}$.

For each formulation, $1 \%(\mathrm{v} / \mathrm{v})$ of starter suspension was added to the almond milk and subsequently incubated at $37{ }^{\circ} \mathrm{C}$ until $\mathrm{pH}$ values of 4.4-4.6 were reached, which was controlled by using a GLP 21+ pH-meter (Crison Instruments S.A.; Barcelona, Spain). The fermented samples were frozen and stored at $-22{ }^{\circ} \mathrm{C}$ prior to analysis. A non-fermented almond sample was used as a control (C).

\subsection{Simulated gastrointestinal digestion}

The human gastrointestinal digestion process was simulated by using porcine pepsin (8002, 500 units/mg protein), pancreatin (activity, 4_USP specifications) and bile, as previously described by Laparra, Barbera, Alegria, Glahn, and Miller (2009). All reagents were purchased from Sigma-Aldrich Co. (St Louis, MO, USA). Prior to the in vitro digestion, $1.5 \mathrm{~mL}$ aliquot of each assayed sample was diluted in $5 \mathrm{~mL}$ of a saline solution $(140 \mathrm{mmol} / \mathrm{L} \mathrm{NaCl}, 5 \mathrm{mmol} / \mathrm{L} \mathrm{KCl} \mathrm{ad-}$ justed to $\mathrm{pH} 3$ ). For gastric digestion (pepsin in $0.1 \mathrm{~mol} / \mathrm{L} \mathrm{HCl}$ adjusted to $\mathrm{pH} 3 ; 1 \mathrm{~h}$ ), samples were placed on a rocking platform shaker in an incubator $\left(37{ }^{\circ} \mathrm{C} ; 5 \% \mathrm{CO}_{2} ; 95 \%\right.$ relative humidity). The intestinal digestion (pancreatin-bile extract in $0.1 \mathrm{~mol} / \mathrm{L} \mathrm{NaHCO}_{3}$ adjusted to $\mathrm{pH}$ 6.9-7; 
$2 \mathrm{~h}$ ) was carried out in the upper chamber of a two-chamber system in 6 -well plates.

The upper chamber was formed by fitting the bottom of an appropriately sized Transwell insert ring (Corning B.V. Life Sciences, Amsterdam, The Netherlands) with a 15,000 molecular mass cut-off dialysis membrane (Spectra/Por 2.1, Spectrum Medical, Gardena, CA, USA). Aliquots $(1.5 \mathrm{~mL})$ of the gastrointestinal digest were loaded into the upper chambers and incubated for $2 \mathrm{~h}$. Afterwards, the inserts were removed and the dialysates were diluted $(1: 4, \mathrm{v} / \mathrm{v})$ with culture media and incubated with intestinal epithelial (Caco-2) or macrophage (RAW 264.7) cells.

\subsection{Ferritin analysis in intestinal epithelial cell monolayer}

Caco-2 cells were obtained from the American Type Culture Collection (Rockville, MD, USA) at passage 17 and used in experiments at passages 33 to 38 . Cells were maintained with Dulbecco's modified Eagle's medium (DMEM) (Gibco ${ }^{\circledR}$, Madrid, Spain) under conditions previously described by Glahn et al. (1998).

For the assays, Caco- 2 cells were seeded at 50,000 cell $/ \mathrm{cm}^{2}$ in collagen-treated 6 -well culture plates (Costar, Cambridge, MA, USA), and were grown with DMEM for 12 days. On the day prior to the experiments, the DMEM medium was replaced by $2 \mathrm{~mL}$ of minimum essential medium (MEM) (Gibco ${ }^{\circledR}$, Madrid, Spain) and then the cells were returned to the incubator. $50 \mu \mathrm{mol} / \mathrm{L}$ of $\mathrm{FeCl}_{3}$ were added to the digested almond milk samples and the ferritin formation by Caco- 2 cells over a $24 \mathrm{~h}$ period was proportional to the cell iron uptake. A latex-enhanced turbidimetric immunoassay (Ferritin-turbilatex; Spinreact, Girona, Spain) was used to measure the Caco-2 cell ferritin content, as Glahn et al. (1998) described. The concentrations of ferritin were normalized by the determination of the total protein content in cell cultures by using a microLowry kit (TP0200) (Sigma-Aldrich, St. Louis, MO, USA). The control cells (basal), exposed to in vitro digestions of control solutions containing digestive enzymes but not sample, were monitored throughout. Base-line cell ferritin in cul- tures grown in MEM averaged $4.2 \mathrm{ng} / \mathrm{mg}$ cell protein. The samples were analyzed in triplicate.

\subsection{Mitochondria enzyme activities}

These activities were evaluated in Caco-2 cell cultures by monitoring MTT (3-(4,5dimethylthiazol-2-yl)-2,3-diphenyl tetrazolium bromide) conversion on exposed cultures after an incubation period of $3 \mathrm{~h}$, following the method described by Laparra et al. (2009). This colorimetric method is based on the reduction of the tetrazolium ring of MTT by mitochondria dehydrogenases yielding a blue formazan product, which can be measured spectrophotometrically. For the assays, Caco- 2 cells were seeded at 50,000 cell $/ \mathrm{cm}^{2}$ in 24 -well culture plates (Costar, Cambridge, MA, USA), and were grown with DMEM for 12 days. Control cells (basal) exposed to digests containing enzymes but not samples were used throughout each assay. Four replicates were analyzed.

\subsection{Analysis of pro-inflammatory markers}

The inflammatory analyses were carried out following the method described by Novak et al. (2003). For the assays, RAW 264.7 cells were seeded at 50,000 cell $/ \mathrm{cm}^{2}$ and were grown with Roswell Park Memorial Institute (RPMI) medium (Gibco ${ }^{\circledR}$, Madrid, Spain) for 24 hours. Tumor Necrosis Factor- $\alpha$ (TNF- $\alpha)$ and interleukin 6 (IL-6) (eBioscience Ltd., Hatfield, UK) were determined by ELISA, following the manufacturer's instructions, on exposed RAW 264.7 cell cultures after an incubation period of $3 \mathrm{~h}$. Results were expressed as picograms per $\mathrm{mL}$ of media. Four replicates were analyzed.

\subsection{Statistical analysis}

Each of the experiments was conducted on four independent replicates. A one-way analysis of variance (ANOVA) and the Tukey post hoc test were applied. Statistical significance was established at a confidence level of $95 \%$ for all the 
Fermented almond milks improve bioavailability of iron $\mid 53$

comparisons. SPSS v.15 software (SPSS Inc., Chicago, IL, USA) was used for the statistical analysis.

\section{Results and Discussion}

\subsection{Almond milk and their fermented-derivative products}

The use of high pressure homogenization ( $\mathrm{HPH}$ ) contributed to a better stability of the almond milk, since this emergent microfluidization technology is able to reduce the size of fat globule particles, greatly delaying the flocculation and coagulation phenomena (Lujan Capra et al., 2009; Cruz et al., 2009).

The chemical composition of the almond milk used for fermentations, which is subsequently codified as control (C), is summarized in Table 1. Taking into account the nut:water ratio used, these values are similar to those found in the literature (Yada, Lapsley, \& Huang, 2011).

The initial $\mathrm{pH}$ of the almond milk $(\mathrm{C})$ was 6.61 \pm 0.08 . A significant decline in $\mathrm{pH}$ to $4.60 \pm 0.02$ after $20 \mathrm{~h}$ at $37^{\circ} \mathrm{C}$ of incubation, took place in the developed products along with a corresponding increase in acidity caused by fermentation.

Table 1: Chemical composition of almond milks used in the study. Values (mean \pm standard deviation) are expressed as grams per $100 \mathrm{~mL}$ of beverage.

\begin{tabular}{cc}
\hline Compound & Concentration \\
\hline Dry matter & $6.64 \pm 0.5$ \\
Lipids & $3.96 \pm 0.2$ \\
Proteins & $1.37 \pm 0.03$ \\
Total sugars & $0.41 \pm 0.002$ \\
Ashes & $0.325 \pm 0.012$ \\
Fiber & $0.58^{*}$ \\
\hline
\end{tabular}

* Fiber concentration was obtained by subtracting the dry matter content from the sum of the rest of compounds shown.

\subsection{Bacterial fermentation effects on TNF $\alpha$ and IL-6 production}

Figure 1 shows the Tumor necrosis factor (TNF)- $\alpha$ and interleukin (IL)-6 production in macrophage (RAW 264.7 cells) cultures exposed to digests of fermented milks. A non-fermented almond milk was used as a control (C).

Focusing on the cells treated with dialyzable fraction samples not fermented by using bifidobacteria (F1 to F5) (Table 2), fermentation with either L. rhamnosus (F2) or L. plantarum (F3) decreased the TNF- $\alpha$ production $(\mathrm{p}<0.05)$ by a similar amount with respect to the control (C). When the standard yoghurt bacteria was used (F1), the TNF- $\alpha$ production was similar to the control. Opposite effects were observed when the fermentation was developed by combining those lactobacilli with standard yoghurt bacteria (F4 and F5, respectively), since the TNF- $\alpha$ production increased $(\mathrm{p}<0.05)$ compared to the control (Figure 1). As regards the IL-6, and contrary to that observed in TNF- $\alpha$, all samples had a positive effect in the production of this proinflammatory marker with respect to the control, especially when the almond milk fermentation was done by using mixed-cultures (F4 and F5). These samples exhibited the lowest IL- 6 concentrations $(\mathrm{p}<0.05)$, showing $55-70 \%$ of inhibition $(\mathrm{p}<0.05)$ of the initial IL-6 production induced by non-fermented almond milk (C) (Figure 1).

With respect to the samples fermented using the bifidobacteria (F6 to F11), all the cells exposed to those dialyzed samples exhibited a very low TNF- $\alpha$ production in comparison to the control $(\mathrm{p}<0.05)$. When considering IL-6 production, different patterns were observed depending on the type of bifidobacteria present in starter. As Figure 1 shows, the fractions from fermented samples with B. bifidum (F6, F8 and F10) induced cells to produce IL-6 amounts similar to that obtained in fermented samples with standard yoghurt bacteria (F1). However, with $B$. longum (F7, F9 and F11) lower $(\mathrm{p}<0.05)$ IL-6 concentrations were quantified, especially when it was combined with either standard yoghurt bacteria (F7) or L. plantarum (F11).

TNF- $\alpha$ is a pro-inflammatory factor produced by macrophages that exerts important effects on 
$54 \mid$ Bernat et al.

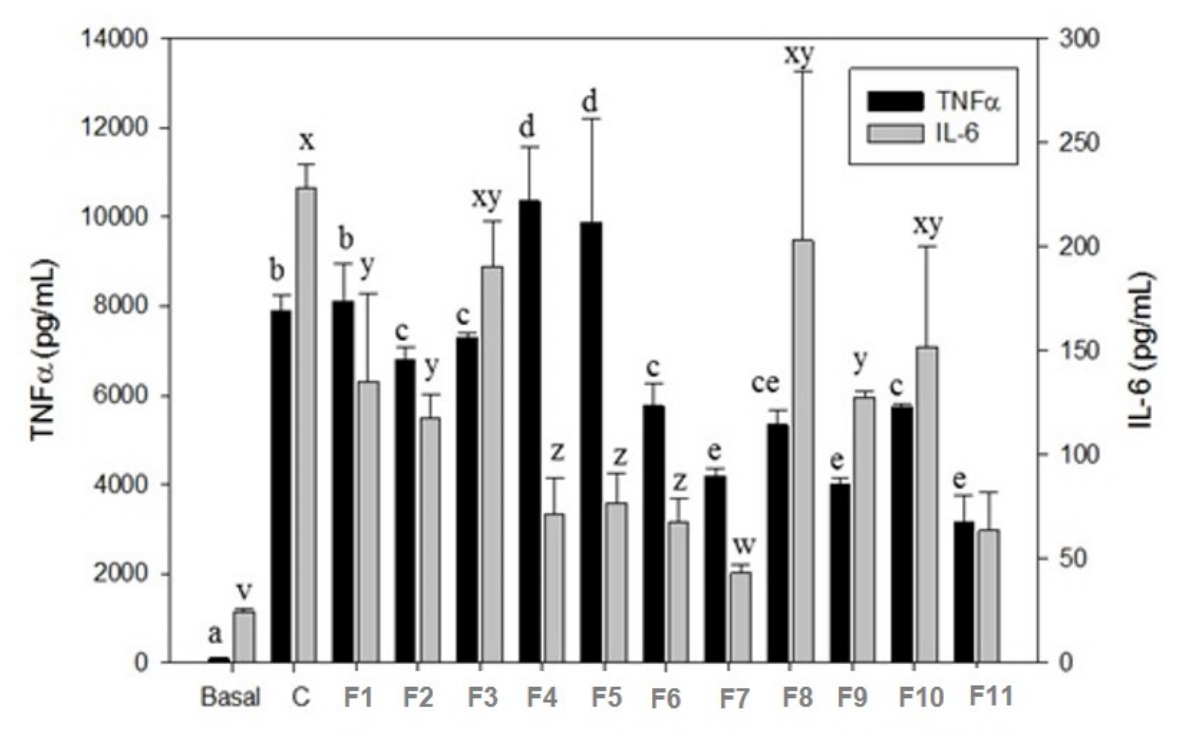

Figure 1: Tumor necrosis factor (TNF)- $\alpha$ and interleukin (IL)-6 production in macrophage (RAW 264.7 cells) cultures exposed to digests of fermented milks. C: non-fermented almond milk. Basal: cells not exposed to samples.* a-e Different superscript letters indicate significant differences between samples in TNF- $\alpha$ production $(\mathrm{p}<0.05){ }^{*}{ }^{\mathrm{w}-\mathrm{z}}$ Different superscript letters indicate significant differences between samples in IL-6 production $(\mathrm{p}<0.05)$.

Table 2: Microbial strains used to produce the different fermented almond milks.

\begin{tabular}{cccc}
\hline Formulation & \multicolumn{2}{c}{ Starters inoculum } \\
\hline C & - & - & - \\
F1 & - & - & S. thermophilus + L. delbrueckii \\
F2 & L. rhamnosus & - & - \\
F3 & L. plantarum & - & S. thermophilus + L. delbrueckii \\
F4 & L. rhamnosus & - & S. thermophilus + L. delbrueckii \\
F5 & L. plantarum & - & S. thermophilus + L. delbrueckii \\
F6 & - & B. bifidum & S. thermophilus + L. delbrueckii \\
F7 & - & B. longum & - \\
F8 & L. rhamnosus & B. bifidum & - \\
F9 & L. rhamnosus & B. longum & - \\
F10 & L. plantarum & B. bifidum & \\
F11 & L. plantarum & B. longum & \\
\hline
\end{tabular}
L.: Lactobacillus
B.: Bifidobacterium
S.: Streptococcus 
Fermented almond milks improve bioavailability of iron $\mid 55$

systemic inflammation and induces the production of other inflammatory cytokines such as IL6 or IL-8 (Hu, Kobayashi, Zenda, \& Shimamura, 1997). The observed bacterial fermentation effects could have important consequences on the intestinal barrier function because TNF- $\alpha$ plays a crucial role by increasing paracellular permeability and impairing tight junction functionality (Ma et al., 2004) and leukocyte infiltration in the intestinal wall (Hoffman, 2000). In addition, the reduction in TNF- $\alpha$ production might also have important physiological consequences preventing allergic inflammatory processes.

Almonds are known to have several nutritional benefits, including that of lowering cholesterol and protection against diabetes (Rajaram et al., 2010; Sabaté et al., 2003). Furthermore, scientific studies have pointed to their potential prebiotic and anti-inflammatory activities (Rajaram et al., 2010; Mandalari et al., 2008). Almond lipids and carbohydrates available for fermentation have been associated with increasing both the number of bifidobacteria strains and the short chain fatty acids (SCFA) content, especially in butyrate concentrations (Mandalari et al., 2008). Butyric acid has the potential to benefit colonic health, since it reduces hydrogen peroxide in cells and maintains their integrity (Scott, Martin, Duncan, \& Flint, 2014). Although bifidobacteria strains are not able to produce butyrate, they synthesize other SCFA such as acetate which can be used by other bacteria (i.e. lactobacilli) in their metabolic route to synthesize this cells' protective acid (Falony, Vlachou, Verbrugghe, \& De Vuyst, 2006). Moreover, this butyric production may be enhanced in the presence of prebiotics (i.e. almond fibers) (Falony et al., 2006; Scott et al., 2014). These facts are coherent and might explain the marked positive effects observed in the inflammatory responses induced by dialysates from samples inoculated with bifidobacteria. Nevertheless, the active components above mentioned (SCFA and prebiotics) have not been analysed since they were beyond the objective of this study.

As the results suggest, the involvement of either $B$. bifidum or $B$. longum in the development of fermented almond-based products might be of interest in order to reduce inflammatory intestinal processes of a targeted population. In- deed, previous in vitro and in vivo studies carried out by using these bacteria species also showed positive effects in immunomodulatory responses (Laparra, Olivares, Gallina, \& Sanz, 2012; Laparra \& Sanz, 2010). Nevertheless, despite the results, the differences from different probiotic strains used are yet to be investigated in detail.

\subsection{Bacterial fermentation effects on energetic metabolism of intestinal cells}

Results of the possible toxicity of fermented samples in intestinal epithelial (Caco-2) cells, which was quantified by monitoring the mitochondrial enzyme (MTT test) activities, are shown in Figure 2. The intestinal epithelium constitutes the first physiological barrier to exogenous compounds and nutrient absorption. Mitochondria and endo-lysosomal enzyme activities were proven to be sensitive biomarkers of changes in cellular metabolism in response to internalized food-derived compounds (Laparra et al., 2009; Wu et al., 2010). This MTT assay showed that none of the dialysates exposed to cell cultures seem to cause toxic effects, as concluded from the fact that the MTT values were similar $(\mathrm{p}<0.05)$ to those calculated for basal culture (cells not exposed to almond milk samples). As mentioned above, possible synergism between almond constituents (prebiotics) and starter bacteria might have produced cell protective bioactive compounds (i.e. butyrate) (Falony et al., 2006; Scott et al., 2014) which prevented alterations of the Caco-2 mythocondria and endo-lyososomal enzymatic activity.

Particularly, the MTT values showed that dialysates from samples fermented with $L$. plantarum 309 (F3) (Table 2) stimulated the energetic cell metabolism, similar to that of nonfermented almond milk (C) $(\mathrm{p}<0.05)$. However, when these bacteria were used in combination with standard yoghurt bacteria, the resulted dialysates (F4 and F5) did not have this significant stimulatory effect.

Both MTT results (Figure 2) and the ones obtained in the production of pro-inflammatory cytokines by immune cells (Figure 1 ) indicated that almond fermented products might exert benefi- 
56 Bernat et al.

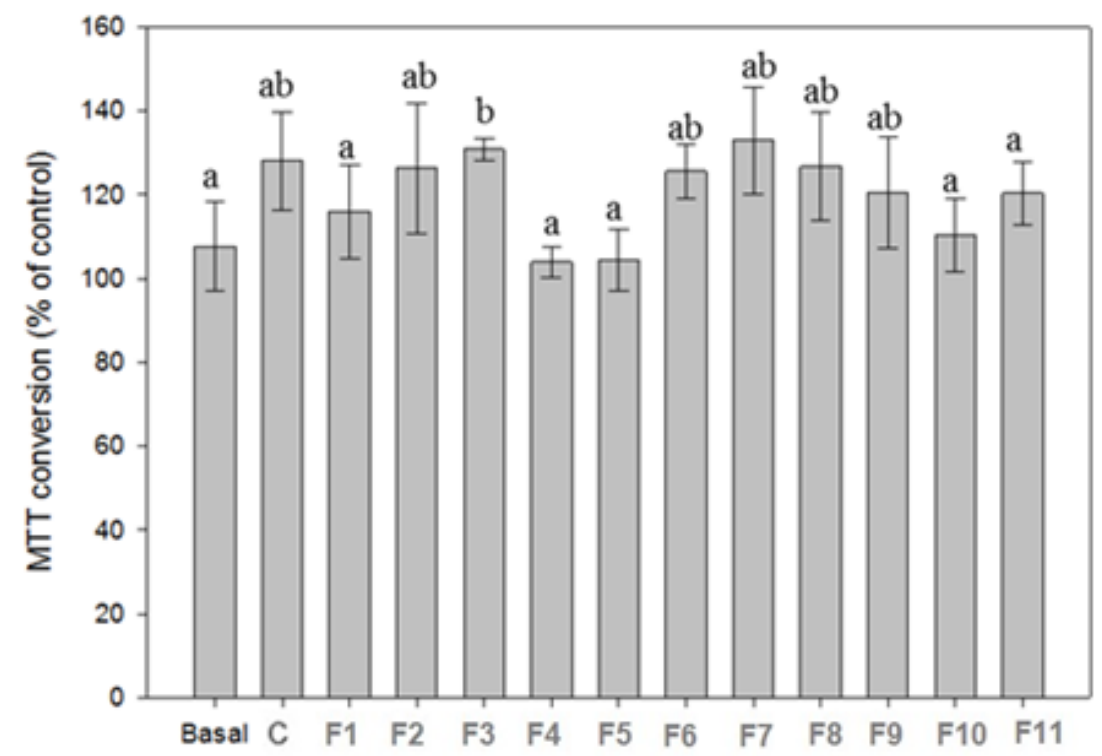

Figure 2: MTT conversion percentages in Caco-2 cell cultures exposed to digests of fermented milks. (C: non-fermented almond milk; Basal: cells not exposed to samples). ${ }^{*}$ a,b Different superscript letters indicate significant differences $(\mathrm{p}<0.05)$ between samples.

cial effects on human gut health, especially when using standard yoghurt bacteria with $B$. longum (F7) and L. rhamnosus with B. longum (F9) as starters.

\subsection{Iron uptake in the presence of fermented almond milk}

Ferritin concentrations in cell cultures exposed to different dialyzed fermented almond milks are shown in Figure 3. Apparently, the fermentation process improved the bioavailability of iron, since the resultant Caco-2 iron uptake in every fermented formulation was higher than that obtained in the cells exposed to non-fermented almond milk dialysates $(\mathrm{C})(\mathrm{p}<0.05)$. In particular, samples fermented with $L$. rhamnosus, with either B. bifidum (F8) or B. longum (F9), were the ones which induced the most iron uptake $(\mathrm{p}<0.05)$. Previous studies have also shown the in vitro enhancing effect of probiotic bacteria on iron uptake in fermented vegetable ma- trices, such as carrot juice (Bergqvist, Andlid, \& Sandberg, 2006), maize (Proulx \& Reddy, 2007) or beans (Laparra, Tako, Glahn, \& Miller, 2008). This study, hence, extends the bacterialmediated positive effects on iron uptake from fermented vegetable products, particularly those in which the starter culture contains bifidobacteria strains. In addition, it has been reported that almond extracts exhibited excellent metal ion chelation efficacies (ability to maintain oligoelements such as iron in the reduced form needed to be absorbed by the epithelial cells), owing to its source of bioactive polyphenols with antioxidant activity (Garrido, Monagas, GomezCordoves, \& Bartolome, 2008; Wijeratne, AbouZaid, \& Shahidi, 2006). These almond-derived components with functional characteristics may also be present in the fermented samples and might explain, at least in part, the effects observed.

Therefore, as Figure 3 suggested, fermented almond milk may provide health benefits to 
Fermented almond milks improve bioavailability of iron $\mid 57$

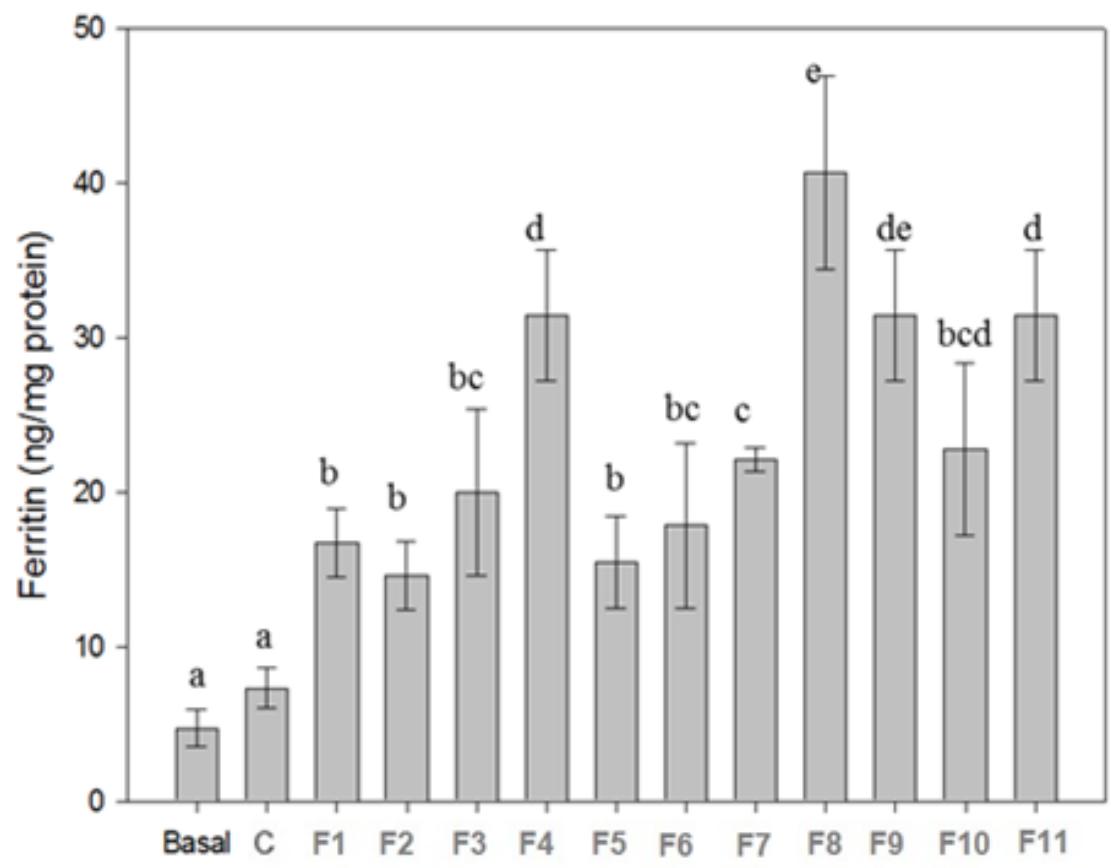

Figure 3: Ferritin concentration in Caco-2 cultures exposed to digested fermented milks with added $\mathrm{FeCl}_{3}(50 \mu \mathrm{mol} / \mathrm{L})$. (MEM: Minimum Essential Medium; C: non-fermented almond milk; Basal: cells not exposed to samples). ${ }^{\text {a,e }}$ Different superscript letters indicate significant differences $(\mathrm{p}<0.05)$ between samples.

consumers owing to its ability to increase the bioavailability of dietary iron. Moreover, this positive effect observed could have important consequences as fermented almond milk might preserve the nutritional iron status in the pediatric community which appears to be the most susceptible population to the negative effects of cow-milk. Furthermore, the intake of this type of product could reduce allergies and intolerances derived from the consumption of cow-milk by this population (Agostoni \& Turck, 2011).

\section{Conclusions}

This study has shown that almond milk fermented with potentially probiotic bacteria exerted positive immunomodulatory effects on macrophages and did not impair negative effects on the energetic metabolism of intestinal epithe- lial cells, especially when this vegetable milk was fermented with either standard yoghurt bacteria and B. longum CECT 4551 or L. rhamnosus CECT 278 and B. longum. Moreover, some combinations of specific strains had markedly significant positive effects on the iron uptake by intestinal epithelial cells that could help to improve the nutritional status of targeted consumers. In particular, samples inoculated with L. rhamnosus CECT 278 and either B. bifidum CECT 870 or B. longum CECT 4551 exhibited the highest ferritin concentrations in Caco-2 cultures. The obtained results also suggest an improvement in the bioactivity of almond milk due to fermentation; nevertheless, the identification of biologically active components is needed and will provide further insights into the potential nutritional and health benefits of fermented almond-based products. To sum up, the results suggest that almond milk fermented with potentially probiotic bacte- 
ria may be beneficial for human gut health and, hence, might be helpful in managing cow-milk allergies and/or intolerances.

\section{Acknowledgements}

This research has been carried out thanks to a funded project by the Universitat Politècnica de València (PAID-05-11-2740). This work was also supported by the Conselleria de Educación of Valencia government, which granted the author N. Bernat (ACIF/2011).

\section{References}

Agostoni, C. \& Turck, D. (2011). Is cow's milk harmful to a child's health? Journal of Pediatric Gastroenterology and Nutrition, 53(6), 594-600. doi:10.1097/MPG. 0b013e318235b23e

Amorocho Cruz, C. M. (2011). Caracterización y potencial probiótico de bacterias lácticas aisladas de leche de oveja guirra (Doctoral dissertation, Universitat Politècnica de València).

Anandan, C., Nurmatov, U., van Schayck, O. C. P., \& Sheikh, A. (2010). Is the prevalence of asthma declining? systematic review of epidemiological studies. Allergy, 65(2), 152-167. doi:10.1111/j.1398-9995. 2009.02244.x

Annunziata, A. \& Vecchio, R. (2011). Functional foods development in the european market: a consumer perspective. Journal of Functional Foods, 3(3), 223-228. doi:10.1016/j. jff.2011.03.011

Artazcoz, M. G.-O. (2007). Lactancia artificial: técnica, indicaciones, fórmulas especiales. Pediatría Integral, 11 (4), 318-326.

Baroja, M. L., Kirjavainen, P. V., Hekmat, S., \& Reid, G. (2007). Anti-inflammatory effects of probiotic yogurt in inflammatory bowel disease patients. Clinical and Experimental Immunology, 149(3), 470-479. doi:10 . 1111/j.1365-2249.2007.03434.x

Bergqvist, S. W., Andlid, T., \& Sandberg, A.-S. (2006). Lactic acid fermentation stimulated iron absorption by caco- 2 cells is associated with increased soluble iron content in carrot juice. British Journal of Nutrition, 96(4), 705-711. doi:10.1079/BJN20061905

Björkstén, B. (2009). Disease outcomes as a consequence of environmental influences on the development of the immune system. Current Opinion in Allergy and Clinical Immunology, 9(3), 185-189. doi:10.1097/ACI. 0b013e32832abfc2

Chen, C.-Y., Lapsley, K., \& Blumberg, J. (2006). A nutrition and health perspective on almonds. Journal of the Science of Food and Agriculture, 86(14), 2245-2250. doi:10. $1002 /$ jsfa. 2659

Cruz, N. S., Capellas, M., Jaramillo, D. P., Trujillo, A. J., Guamis, B., \& Ferragut, V. (2009). Soymilk treated by ultra highpressure homogenization: acid coagulation properties and characteristics of a soyyogurt product. Food Hydrocolloids, 23(2), 490-496. doi:10.1016/j. foodhyd.2008.03. 010

Deepika, G., Rastall, R. A., \& Charalampopoulos, D. (2011). Effect of food models and low-temperature storage on the adhesion of lactobacillus rhamnosus gg to caco- 2 cells. Journal of Agricultural and Food Chemistry, 59(16), 8661-8666. doi:10 . 1021/ jf2018287

Falony, G., Vlachou, A., Verbrugghe, K., \& De Vuyst, L. (2006). Cross-feeding between bifidobacterium longum bb536 and acetateconverting, butyrate-producing colon bacteria during growth on oligofructose. Applied and Environmental Microbiology, 72(12), 7835-7841. doi:10 . 1128/AEM . 01296-06

Garrido, I., Monagas, M., Gomez-Cordoves, C., \& Bartolome, B. (2008). Polyphenols and antioxidant properties of almond skins: influence of industrial processing. Journal of Food Science, 73(2), C106-C115. doi:10 . 1111/j.1750-3841.2007.00637.x

Glahn, R. P., Lee, O. A., Yeung, A., Goldman, M. I., \& Miller, D. D. (1998). Caco-2 cell ferritin formation predicts nonradiolabeled food iron availability in an in vitro digestion caco-2 cell culture model. Journal of Nutrition, 128(9), 1555-1561.

Hoffman, R. A. (2000). Intraepithelial lymphocytes coinduce nitric oxide synthase in in- 
Fermented almond milks improve bioavailability of iron $\mid 59$

testinal epithelial cells. American Journal of Physiology-gastrointestinal and Liver Physiology, 278(6), G886-G894.

Hu, Z. Q., Kobayashi, K., Zenda, N., \& Shimamura, T. (1997). Tumor necrosis factoralpha- and interleukin-6-triggered mast cell development from mouse spleen cells. Blood, 89(2), 526-533.

Kabeerdoss, J., Devi, R. S., Mary, R. R., Prabhavathi, D., Vidya, R., Mechenro, J., .. Ramakrishna, B. S. (2011). Effect of yoghurt containing bifidobacterium lactis bb12 (r) on faecal excretion of secretory immunoglobulin a and human beta-defensin 2 in healthy adult volunteers. Nutrition Journal, 10. doi:10.1186/1475-2891-10-138

Kalliomäki, M. (2010). Probiotics, prebiotics and synbiotics: a hope or hype in allergy? Clinical and Experimental Allergy, 40(5), 694696. doi:10.1111/j.1365-2222.2010.03471.x

Kalliomäki, M., Antoine, J.-M., Herz, U., Rijkers, G. T., Wells, J. M., \& Mercenier, A. (2010). Guidance for substantiating the evidence for beneficial effects of probiotics: prevention and management of allergic diseases by probiotics. Journal of Nutrition, 140(3), 713S-721S. Workshop on Guidance for Assessing Probiotics Beneficial Effects How to Fill the GAP, ILSI, Europe Assoc Int Dairy Federat, Montreux, SWITZERLAND, MAY 22-24, 2008. doi:10.3946/jn. 109.113761

Laparra, J. M. \& Sanz, Y. (2010). Bifidobacteria inhibit the inflammatory response induced by gliadins in intestinal epithelial cells via modifications of toxic peptide generation during digestion. Journal of Cellular Biochemistry, 109(4), 801-807. doi:10.1002/ jcb. 22459

Laparra, J. M., Barbera, R., Alegria, A., Glahn, R. P., \& Miller, D. D. (2009). Purified glycosaminoglycans from cooked haddock may enhance fe uptake via endocytosis in a caco-2 cell culture model. Journal of Food Science, 74 (6), H168-H173. doi:10.1111/j. 1750-3841.2009.01216.x

Laparra, J. M., Olivares, M., Gallina, O., \& Sanz, Y. (2012). Bifidobacterium longum cect 7347 modulates immune responses in a gliadin-induced enteropathy animal model.
Plos One, 7(2). doi:10.1371/journal.pone. 0030744

Laparra, J. M., Tako, E., Glahn, R. P., \& Miller, D. D. (2008). Inulin affects iron dialyzability from feso 4 and feedta solutions but does not alter fe uptake by caco- 2 cells. Journal of Agricultural and Food Chemistry, 56(8), 2846-2851. doi:10.1021/jf073470m

Luengo, M. (2009). La almendra y otros frutos secos: castaña, pistacho, piñon, nuez. Buenos Aires: Oceano-Ambar.

Lujan Capra, M., Patrignani, F., del Lujan Quiberoni, A., Alberto Reinheimer, J., Lanciotti, R., \& Guerzoni, M. E. (2009). Effect of high pressure homogenization on lactic acid bacteria phages and probiotic bacteria phages. International Dairy Journal, 19(5), 336-341. doi:10.1016/j.idairyj. 2008.11.002

Ma, T. Y., Iwamoto, G. K., Hoa, N. T., Akotia, V., Pedram, A., Boivin, M. A., \& Said, H. M. (2004). Tnf-alphainduced increase in intestinal epithelial tight junction permeability requires nf-kappa b activation. American Journal of Physiology-gastrointestinal and Liver Physiology, 286(3), G367-G376. doi:10.1152/ajpgi.00173.2003

Mandalari, G., Nueno-Palop, C., Bisignano, G., Wickham, M. S. J., \& Narbad, A. (2008). Potential prebiotic properties of almond (amygdalus communis 1.) seeds. Applied and Environmental Microbiology, $74(14)$, 4264-4270. doi:10.1128/AEM.00739-08

Miret, S., Simpson, R. J., \& McKie, A. T. (2003). Physiology and molecular biology of dietary iron absorption. Annual Review of Nutrition, 23, 283-301. doi:10 . 1146/ annurev.nutr.23.011702.073139

Novak, T. E., Babcock, T. A., Jho, D. H., Helton, W. S., \& Espat, N. J. (2003). Nf-kappa b inhibition by omega-3 fatty acids modulates lps-stimulated macrophage tnf-alpha transcription. American Journal of Physiologylung Cellular and Molecular Physiology, 284(1), L84-L89. doi:10 . 1152 / ajplung . 00077.2002

Proulx, A. K. \& Reddy, M. B. (2007). Fermentation and lactic acid addition enhance iron bioavailability of maize. Journal of Agri- 
$60 \mid$ Bernat et al.

cultural and Food Chemistry, 55(7), 27492754. doi:10.1021/jf0630015

Rajaram, S., Connell, K. M., \& Sabate, J. (2010). Effect of almond-enriched highmonounsaturated fat diet on selected markers of inflammation: a randomised, controlled, crossover study. British Journal of Nutrition, 103(6), 907-912. doi:10.1017/ S0007114509992480

Sabaté, J., Haddad, E., Tanzman, J. S., Jambazian, P., \& Rajaram, S. (2003). Serum lipid response to the graduated enrichment of a step i diet with almonds: a randomized feeding trial. American Journal of Clinical Nutrition, 77(6), 1379-1384.

Scott, K. P., Martin, J. C., Duncan, S. H., \& Flint, H. J. (2014). Prebiotic stimulation of human colonic butyrate-producing bacteria and bifidobacteria, in vitro. Fems Microbiology Ecology, 87(1), 30-40. doi:10.1111/ 1574-6941.12186

Sutas, Y., Soppi, E., Korhonen, H., Syvaoja, E. L., Saxelin, M., Rokka, T., \& Isolauri, E. (1996). Suppression of lymphocyte proliferation in vitro by bovine caseins hydrolyzed with lactobacillus casei gg-derived enzymes. Journal of Allergy and Clinical Immunology, 98(1), 216-224. doi:10.1016/ S0091-6749(96)70245-2

Wagar, L. E., Champagne, C. P., Buckley, N. D., Raymond, Y., \& Green-Johnson, J. M. (2009). Immunomodulatory properties of fermented soy and dairy milks prepared with lactic acid bacteria. Journal of Food Science, 74(8), M423-M430. doi:10.1111/ j.1750-3841.2009.01308.x

Wijeratne, S. S. K., Abou-Zaid, M. M., \& Shahidi, F. (2006). Antioxidant polyphenols in almond and its coproducts. Journal of Agricultural and Food Chemistry, 54 (2), 312-318. doi:10.1021/jf052692j

Wu, S.-B., Su, J.-J., Sun, L.-H., Wang, W.-X., Zhao, Y., Li, H., ... Hu, J.-F. (2010). Triterpenoids and steroids from the fruits of melia toosendan and their cytotoxic effects on two human cancer cell lines. Journal of Natural Products, 73(11), 1898 1906. doi:10.1021/np100566v

Yada, S., Lapsley, K., \& Huang, G. (2011). A review of composition studies of cul- tivated almonds: macronutrients and micronutrients. Journal of Food Composition and Analysis, 24(4-5, SI), 469-480. doi:10. 1016/j.jfca.2011.01.007 